\title{
Prolactin Regulates Tuberoinfundibular Dopamine Neuron Discharge Pattern: Novel Feedback Control Mechanisms in the Lactotrophic Axis
}

\author{
David J. Lyons, Arash Hellysaz, and Christian Broberger \\ Department of Neuroscience, Karolinska Institutet, 17177 Stockholm, Sweden
}

Balance in the body's hormonal axes depends on feedback onto neuroendocrine hypothalamic neurons. This phenomenon involves transcriptional and biosynthetic effects, yet less is known about the potential rapid modulation of electrical properties. Here, we investigated this issue in the lactotrophic axis, in which the pituitary hormone prolactin is tonically inhibited by tuberoinfundibular dopamine (TIDA) neurons located in the hypothalamic arcuate nucleus. Whole-cell recordings were performed on slices of the rat hypothalamus. In the presence of prolactin, spontaneously oscillating TIDA cells depolarized, switched from phasic to tonic discharge, and exhibited broadened action potentials. The underlying prolactin-induced current is composed of separate low- and high-voltage components that include the activation of a transient receptor potential-like current and the inhibition of a $\mathrm{Ca}^{2+}$-dependent $\mathrm{BK}$-type $\mathrm{K}^{+}$current, respectively, as revealed by ion substitution experiments and pharmacological manipulation. The two components of the prolactin-induced current appear to be mediated through distinct signaling pathways as the high-voltage component is abolished by the phosphoinositide 3-kinase blocker wortmannin, whereas the low-voltage component is not. This first description of the central electrophysiological actions of prolactin suggests a novel feedback mechanism. By simultaneously enhancing the discharge and spike duration of TIDA cells, increased serum prolactin can promote dopamine release to limit its own secretion with implications for the control of lactation, sexual libido, fertility, and body weight.

\section{Introduction}

The polypeptide hormone prolactin (Prl) (Riddle et al., 1933) triggers lactation in the nursing mother and exerts a range of coordinated actions that facilitate caring for offspring, including maternal behavior, temporal spacing of pregnancies, and weight gain (Freeman et al., 2000). Whereas other pituitary hormones depend on hypothalamic stimulating factors for release, Prlproducing lactotrophs, cells with high constitutive activity (Van Goor et al., 2001), are under most circumstances maintained under hypothalamic inhibition (Ben-Jonathan and Hnasko, 2001). This inhibitory tone is provided by neuroendocrine tuberoinfundibular dopamine (TIDA) neurons located in the arcuate nucleus (Arc) (Fuxe, 1964). The strength of this inhibition is illustrated by the fact that treatment with anti-dopaminergic anti-psychotic drugs causes hyperprolactinaemia (Polishuk and Kulcsar, 1956; Meltzer et al., 1974; Knegtering et al., 2006), which likely underlies the high incidence of sexual dysfunctions and

\footnotetext{
Received Jan. 10, 2012; revised March 20, 2012; accepted April 3, 2012.

Author contributions: D.J.L. and C.B. designed research; D.J.L. and A.H. performed research; D.J.L. and A.H. analyzed data; D.J.L. and C.B. wrote the paper.

This study was supported by European Research Council Grant 261286 (ENDOSWITCH) and the Swedish Research Council Grant 2010-3250 (C.B.). D.J.L. was supported by a postdoctoral fellowship from the Wenner-Gren Foundations. We thank Abdel El Manira for invaluable comments during the preparation of this manuscript.

Correspondence should be addressed to either David J. Lyons or Christian Broberger, Department of Neuroscience, Karolinska Institutet, Retzius v. 8, 17177 Stockholm, Sweden. E-mail: David.Lyons@ki.se, Christian.Broberger@ki.se.

DOI:10.1523/JNEUROSCI.0129-12.2012

Copyright $\odot 2012$ the authors $\quad 0270-6474 / 12 / 328074-10 \$ 15.00 / 0$
}

sometimes even overt galactorrhea in patients taking these compounds in, for example, the treatment of schizophrenia (Howes et al., 2007). In a recent in vitro study, we demonstrated that TIDA neurons discharge in a highly robust oscillation that is synchronized between neurons and sensitive to gap junction blockade (Lyons et al., 2010). This stereotyped electrical profile suggests that the membrane properties of TIDA neurons may constitute an important regulatory target in Prl control.

Prl provides powerful, so-called "short-loop," feedback that acts as a safeguard against hyperprolactinaemia (Ben-Jonathan and Hnasko, 2001). To date, this feedback has generally been ascribed to modulating the expression and kinetics of the ratelimiting enzyme in dopamine biosynthesis, tyrosine hydroxylase (TH) (Gonzalez and Porter, 1988; Pasqualini et al., 1988; Arbogast and Voogt, 1991, 1995; Selmanoff et al., 1991). Compared with slow transcriptional and biosynthetic changes, the presumably more rapid electrophysiological effects of Prl on TIDA neurons have yet to be described. Indeed, although a few extracellular recordings have been published (Townsend et al., 2005; Kokay et al., 2006), there is to date no description of Prl actions on active or passive membrane properties in any neuronal system. This lack of information is particularly surprising given the pleiotropic effects of this hormone and the numerous expression sites of Prl receptors in the CNS (Chiu and Wise, 1994; Pi and Grattan, 1998), including TIDA neurons (Kokay and Grattan, 2005). Here, we wanted to explore the mechanisms for fast feedback in the short loop by investigating the effects of Prl on TIDA electrophysiology. 

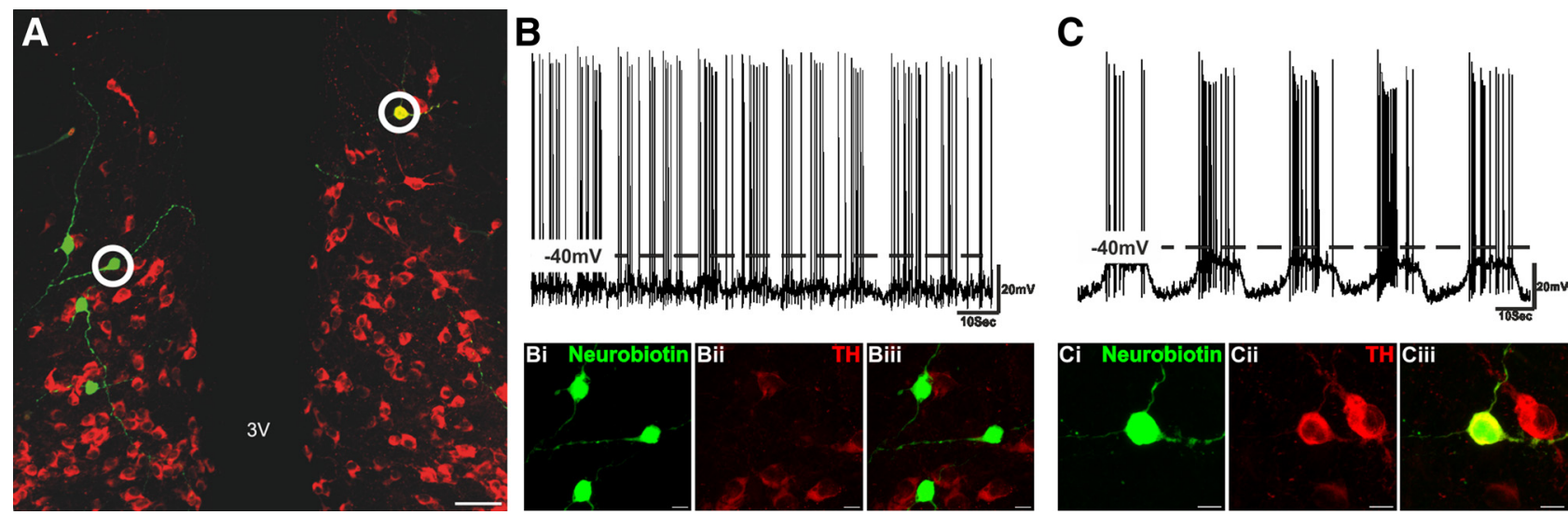

Figure 1. TIDA neurons display rhythmic oscillations. A, Merged confocal stack of a 250- $\mu \mathrm{m}$-thick hypothalamic Arc slice processed with avidin-fluorescein to detect recorded Neurobiotin-filled neurons (green) and stained with immunofluorescence for TH (red) to identify TIDA neurons. Of the four recorded neurons in the left side of the third ventricle (3V), none displayed oscillatory behavior or stained positive for TH immunofluorescence. Scale bar, $50 \mu \mathrm{m}$. B. Current-clamp recording of the circled Neurobiotin-filled neuron from the left side of the 3V; high-magnification micrographs of this neuron shown in Bi-Biii. Note the lack of oscillatory discharge and absence of TH immunoreactivity. C, Current-clamp recording of the circled Neurobiotin-filled neuron from the right side of the $3 \mathrm{~V}$; high-magnification micrographs of this neuron shown in Ci-Ciii. Scale bar, $10 \mu \mathrm{m}$. Note robust regular membrane potential oscillation and colocalization of Neurobiotin and TH immunoreactivity.

\section{Materials and Methods}

Animals. Male Sprague Dawley rats (Charles River), 22-30 d old, were housed with ad libitum access to standard chow and tap water in a temperature-controlled environment under $12 \mathrm{~h}$ light/dark conditions with lights on at 6:00 A.M. For this study of the Prl-inhibitory TIDA cells, we used male rats in which inhibition is likely at its most active and to avoid confounding influence from fluctuations in sex hormones, which are potent endogenous modulators of Prl secretion. All animal experiments had received previous approval by the local ethical board, Stockholm's Norra Djurförsöksetiska Nämnd, and were performed in accordance with the European Communities Council Directive of November 24, 1986 (86/609/EEC).

Whole-cell recordings. For electrophysiological experiments, rats $(n=$ 47) were deeply anesthetized with sodium pentobarbital and decapitated. The brain was rapidly removed and placed in an ice-cold and oxygenated $\left(95 \% \mathrm{O}_{2} / 5 \% \mathrm{CO}_{2}\right)$ "slicing" solution containing the following (in $\mathrm{mM}$ ): 214 sucrose, $2.0 \mathrm{KCl}, 1.2 \mathrm{NaH}_{2} \mathrm{PO}_{4}, 26 \mathrm{NaHCO}_{3}, 1.3 \mathrm{MgSO}_{4}, 2.4 \mathrm{CaCl}_{2}$, and $10 \mathrm{D}$-glucose. The meninges were gently removed, and the brain was blocked and glued to a vibratome (Leica) in which $250-\mu \mathrm{m}$-thick coronal sections of the hypothalamus containing the Arc were prepared. Slices were immediately transferred to a "recording" solution containing the following (in mM): $127 \mathrm{NaCl}, 2.0 \mathrm{KCl}, 1.2 \mathrm{NaH}_{2} \mathrm{PO}_{4}, 26 \mathrm{NaHCO}_{3}, 1.3$ $\mathrm{MgCl}_{2}, 2.4 \mathrm{CaCl}_{2}$, and $10 \mathrm{D}$-glucose (in a continuously oxygenated holding chamber at $35^{\circ} \mathrm{C}$ for a period of $25 \mathrm{~min}$ ). Subsequently, slices were allowed to recover in recording solution at room temperature for a minimum of $1 \mathrm{~h}$ before recording. For whole-cell recordings, slices were transferred to a submerged chamber and placed on an elevated grid that allows perfusion both above and below the slice. An Axioskop 2 FS Plus upright microscope (Carl Zeiss) was used for infrared differential interference contrast visualization of cells. Recordings were performed at room temperature $\left(22^{\circ} \mathrm{C}\right)$, and slices were continuously perfused with oxygenated recording solution (as above) unless otherwise described at a rate of $\sim 5 \mathrm{ml} / \mathrm{min}$. All pharmacological compounds were bath applied.

Whole-cell current- and voltage-clamp recordings were performed with pipettes (5-8 $\mathrm{M} \Omega$ when filled with intracellular solution) made from borosilicate glass capillaries (World Precision Instruments) pulled on a P-97 Flaming/Brown micropipette puller (Sutter Instruments). The intracellular recording solution used in experiments contained $140 \mathrm{~mm}$ K-gluconate, $10 \mathrm{~mm} \mathrm{KCl,} 10 \mathrm{~mm}$ HEPES, $1 \mathrm{~mm}$ EGTA, and $2 \mathrm{~mm}$ $\mathrm{Na}_{2}$ ATP, pH 7.3 (with $\mathrm{KOH}$ ), with $0.2 \%$ Neurobiotin (Vector Laboratories) added for subsequent morphological reconstruction of recorded cells. The concentration used for tetrodotoxin (TTX) was $0.5 \mu \mathrm{M}$. To reduce $\mathrm{Ca}^{2+}$-dependent conductances, "low-Ca ${ }^{2+} /$ high- $\mathrm{Mg}^{2+}$ " extracellular recording solution was used (in $\mathrm{mM}$ ): $127 \mathrm{NaCl}, 1.9 \mathrm{KCl}, 1.2$ $\mathrm{NaH}_{2} \mathrm{PO}_{4}, 26 \mathrm{NaHCO}_{3}, 4.5 \mathrm{MgSO}_{4}, 0.15 \mathrm{CaCl}_{2}$, and 10 D-glucose. To inhibit $\mathrm{Na}^{+}$-dependent conductances, a "zero- $\mathrm{Na}^{+}$” extracellular solution was prepared in which $\mathrm{Na}^{+}$was substituted with equimolar concentrations of Tris- $\mathrm{HCl}$. Recordings were performed using a Multiclamp 700B amplifier and pClamp9 software (Molecular Devices). Slow and fast capacitative components were automatically compensated for. Access resistance was monitored throughout the experiments, and neurons in which the series resistance was $>35 \mathrm{M} \Omega$ or changed $>20 \%$ were excluded from the statistics. Liquid junction potential was $16.4 \mathrm{mV}$ and not compensated. The recorded current was sampled at $10 \mathrm{kHz}$ and filtered at $2 \mathrm{kHz}$.

Statistical analysis and reagents. Data analysis was performed with Originpro8 (OriginLab) and Clampfit (Molecular Devices) software. Statistical significance was set at $p<0.05$ and determined using the appropriate two-tailed Student's $t$ test unless otherwise stated. To determine the Prlinduced current $\left(I_{\mathrm{Prl}}\right)$ in the presence of TTX, all-points histograms were plotted for $10 \mathrm{~s}$ of control, Prl, and wash traces with Gaussian fits performed on the individual and pooled distributions. The mean difference between the Gaussian peaks for control and $\mathrm{Prl}$ was used as the value for $I_{\mathrm{Prl}}$. Action potentials (APs) were analyzed using Mini Analysis 6.0.9 (Synaptosoft). For each neuron, AP values were generated by taking the mean of $10 \mathrm{APs}$ in control and $10 \mathrm{APs}$ in the presence of Prl. To control for the variation in AP properties observed throughout the progression of the depolarizing up state (control), only groups with statistically similar (i.e., $p>0.05$ ) amplitudes and thresholds were used for analysis (see Fig 6). Prl, 2-aminoethyl diphenylborinate (2-APB), and tetraethylammonium (TEA)- $\mathrm{Cl}_{2}$ were purchased from Sigma. TTX was purchased from Alomone Labs. AG490 [( E)-2-cyano3-(3,4-dihydrophenyl)- $N$-(phenylmethyl)-2-propenamide], nimodipine, paxilline, SKF96365 (1-[2-(4-methoxyphenyl)-2-[3-(4-methoxyphenyl) propoxy] ethyl-1 $H$-imidazole hydrochloride), UCL1648 [6,10-diaza$3(1,3) 8,(1,4)$-dibenzena-1,5(1,4)-diquinolinacy clodecaphane], and wortmannin were purchased from Tocris Bioscience.

Reconstruction and staining of recorded cells. Immediately after recording, slices were immersion fixed in $4 \%$ paraformaldehyde $/ 0.2 \%$ picric acid for $16 \mathrm{~h}$ at $4^{\circ} \mathrm{C}$ and rinsed for a minimum of $6 \mathrm{~h}$ in $0.1 \mathrm{~m}$ phosphate buffer, $\mathrm{pH} 7.4$, containing $0.2 \%$ bacitracin and $0.1 \%$ sodium azide. Slices were then incubated free floating with a mixture of fluorescein isothiocyanate-conjugated avidin (1:3000; Invitrogen) and monoclonal anti-TH antibodies (1:1000; Millipore Bioscience Research Reagents) diluted in $0.6 \%$ Triton X-100/0.01 M PBS for $72 \mathrm{~h}$ at $4^{\circ} \mathrm{C}$. After $6 \mathrm{~h}$ of rinsing in PBS, slices were incubated for $16 \mathrm{~h}$ in anti-mouse secondary antibodies raised in donkey and conjugated to Alexa Fluor 594 (Invitrogen) diluted 1:500 in $0.6 \%$ Triton X-100/0.01 м PBS, rinsed for an additional $6 \mathrm{~h}$ in PBS, and mounted and coverslipped on glass slides with glycerol and anti-fade agent (2.5\% 1,4-diazabicyclo[2.2.2] octane). Confocal image stacks were sampled with an Olympus 
FV1000 inverted microscope at the Center for Live Cell Imaging at Karolinska Institutet, and images were analyzed and processed using BitPlane Imaris software. For final images, only brightness and contrast were adjusted digitally.

\section{Results}

TIDA neurons exhibit robust rhythmic membrane potential oscillations

Here, we have recorded from a population of rhythmically discharging neurons in the dorsomedial aspect of the Arc adjacent to the third ventricle. As described previously (Lyons et al., 2010), this oscillation is typified by periods of hyperpolarization and quiescence (down state) alternating with periods of pronounced depolarization and AP discharge (up state; Fig. 1). In line with our previous report, neurons displaying these characteristics were shown to be members of the TIDA population, as when filled with biocytin all recovered oscillator cells were revealed to be TH immunoreactive ( $n=29$ of $29 ; 100 \%$; Fig. 1).

Prl excites oscillating TIDA neurons: replacing phasic discharge with tonic firing

The acute electrophysiological effects of Prl on the TIDA network are not known. To address this issue, TIDA neurons were patch clamped, and their electrophysiological responsiveness to Prl was assessed. In current clamp, a 90-120 s bath application of Prl (25-500 nM) to oscillating neurons consistently resulted in a depolarization and transition from phasic to tonic discharge $(n=21$ of $21 ; 100 \%$; Fig. $2 A)$. This dramatic response can also be seen in the shift from biphasic to monophasic distribution in the membrane potential frequency distribution plot (Fig. $2 B$ ).

In the presence of TTX (500 nM to block AP-dependent postsynaptic potentials) and from a membrane potential of $-65 \mathrm{mV}, \operatorname{Prl}(250 \mathrm{nM})$ induced a reversible $16.3 \pm 2.1 \mathrm{mV}(n=6$; $p<0.001$ vs control, ANOVA) depolarization (Fig. 2C,D), indicating a direct postsynaptic effect that was also dose dependent $\left(\mathrm{EC}_{50}=123.9\right.$ nM; Fig. $\left.2 \mathrm{E}\right)$. The Prl-induced depolarization was associated with a small $6.7 \pm 1.6 \%$ reduction in input resistance (control, $1262.8 \pm 266.4 \mathrm{M} \Omega$; $\operatorname{Prl}, 1185.9 \pm 257.8 \mathrm{M} \Omega ; n=5$; $p<0.05)$ and was shown to exhibit desensitization because, after complete washout and a return to baseline (typically 10-15 $\mathrm{min}$ ), a second application of Prl resulted in a membrane potential change that was diminished by $27.0 \pm 4.1 \%$ $(n=5 ; p<0.05)$.

Prl activates an inward current composed of low- and high-voltage components

To identify the postsynaptic currents underpinning the Prl effect, we voltage clamped TIDA neurons $\left(V_{\mathrm{Hold}}=-60 \mathrm{mV}\right)$ in the
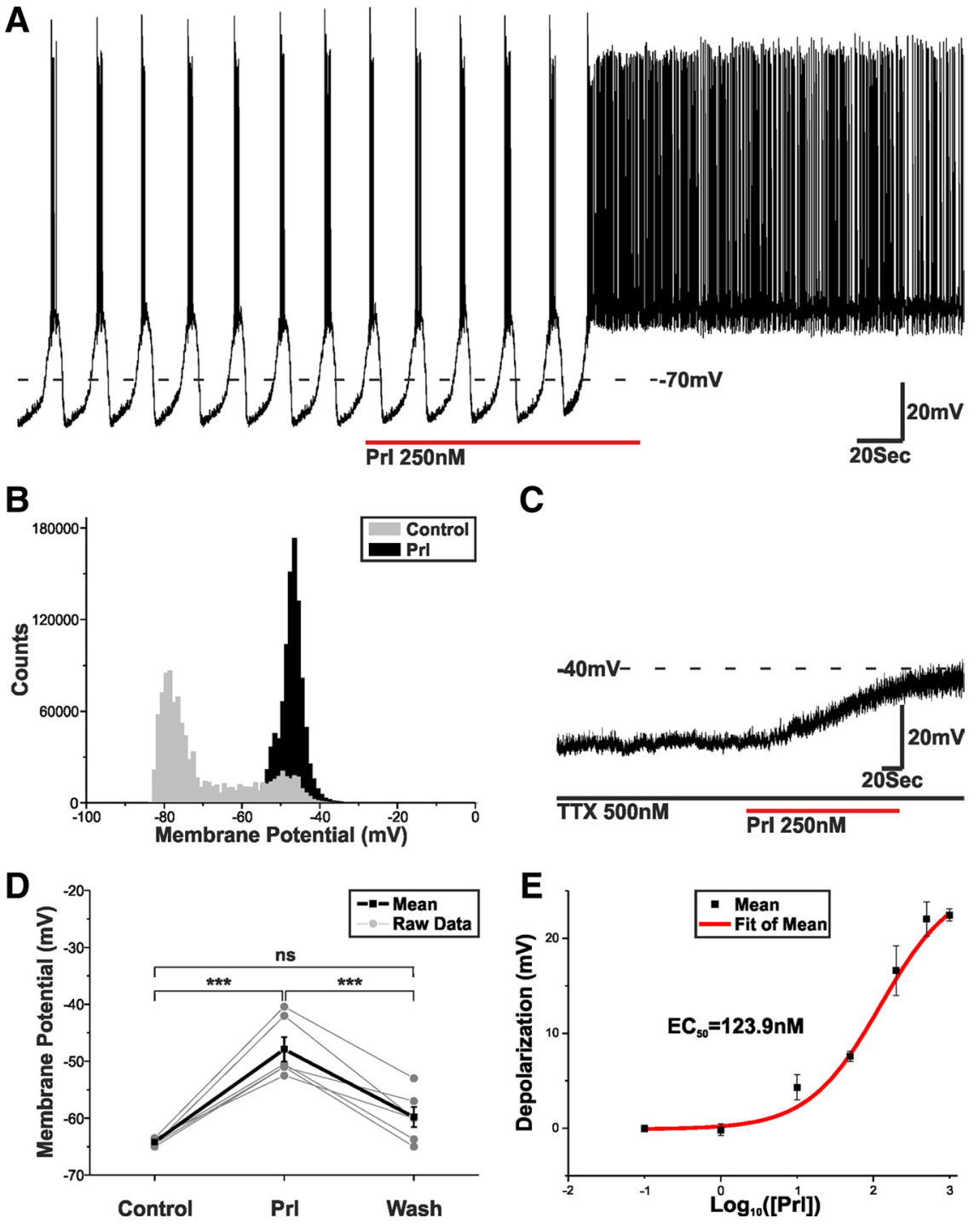

Figure 2. Prlswitches TIDA discharge from phasic to tonic. $A$, Current-clamp recording of an oscillating TIDA neuron. Application of Prl switches TIDA discharge from phasic to tonic. $\boldsymbol{B}$, Frequency distribution plot demonstrating the Prl-induced shift in memtion and the resultant membrane depolarization. Cells included were exposed to single concentrations of Prl in the presence of TTX and from a resting membrane potential of $-65 \mathrm{mV}$.

presence of TTX (500 nM). Application of $\operatorname{Prl}(500 \mathrm{~nm})$ induced an inward current of $-17.4 \pm 2.1 \mathrm{pA}(n=11 ; p<0.001$ vs control, ANOVA) that was readily reversible on washout (Fig. $3 A$ ). A voltage-clamp ramp protocol ranging from -120 to 40 $\mathrm{mV}(45.7 \mathrm{mV} / \mathrm{s})$ was used to determine the $I-V$ relationship of the $I_{\mathrm{Prl}}$ (Fig. $3 B$ ). Digital subtraction of the ramp performed in control from the ramp performed at the peak of the Prl response revealed $I_{\mathrm{Prl}}$ to be a non-reversing net inward current that exhibits a profound increase in size in the positive range $\left(V_{\text {Hold }}=+40\right.$ $\mathrm{mV} ;-328.3 \pm 58.9$ pA; $n=14$; Fig. $3 C)$.

The $I-V$ relationship of $I_{\mathrm{Prl}}$ strongly implies a compound effect mediated by the modulation of more than one current. To facilitate our understanding of this, we divided $I_{\mathrm{Prl}}$ into two components: one below $0 \mathrm{mV}$, termed low voltage ( $\mathrm{LV}$ ), and one above $0 \mathrm{mV}$, termed high voltage (HV) (Fig. $3 \mathrm{C}$, gray shading). Because the LV component of $I_{\mathrm{Prl}}$ tends toward reversal at $0 \mathrm{mV}$ 
A

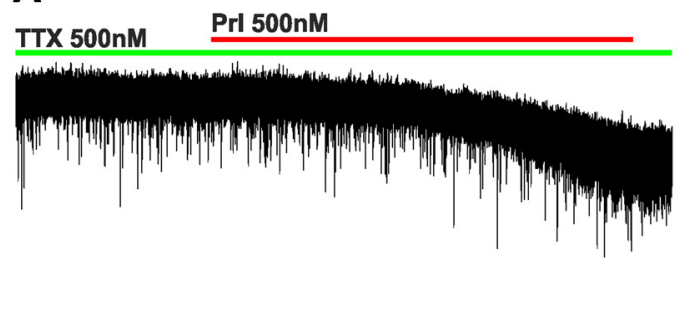

20Sec

B

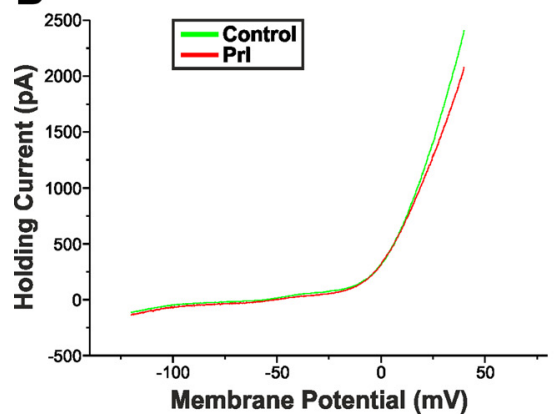

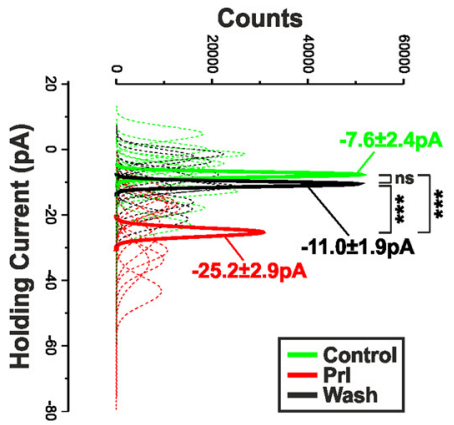

C

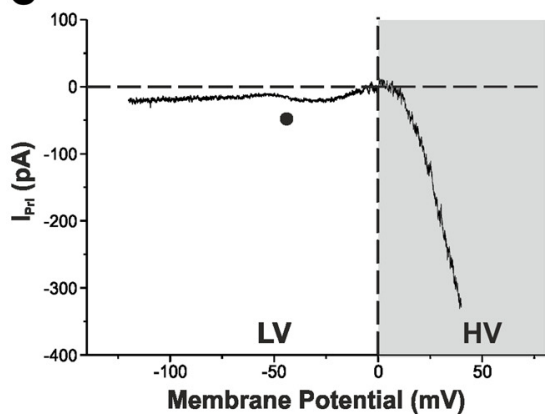

Figure 3. Prl activates an inward current. $\boldsymbol{A}$, Voltage-clamp recording of an oscillating TIDA neuron in the presence of TTX. Application of Prl results in an inward current. To the right, sharing its $y$-axis with the raw trace, are Gaussian fits of averaged (solid lines) holding current frequency distributions in control (green), Prl (red), and wash (black). Raw data used to produce averages shown as dashed lines. ${ }^{* * *} p<0.001$. $\boldsymbol{B}$, Averaged voltage-clamp ramps $(n=14)$ acquired in control (green) and at the peak of the Prl response (red). $C$, Prl-induced current obtained by the digital subtraction of the traces displayed in $\boldsymbol{B}$. Note the negative slope conductance at $-50 \mathrm{mV}(\boldsymbol{O})$, lack of reversal, and increased inward current in the $\mathrm{HV}$ range (gray box).

\section{A}

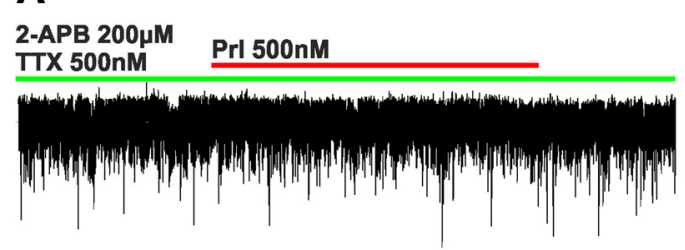

$\underline{20 S e c}$

B

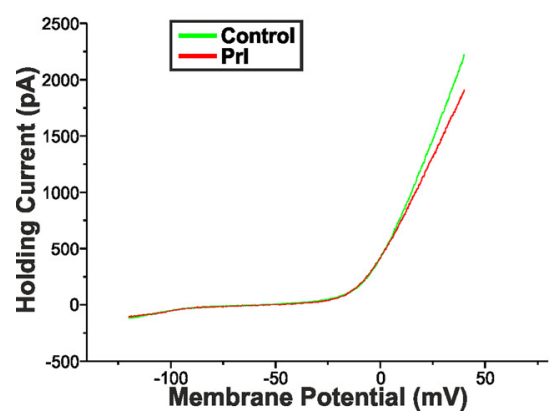

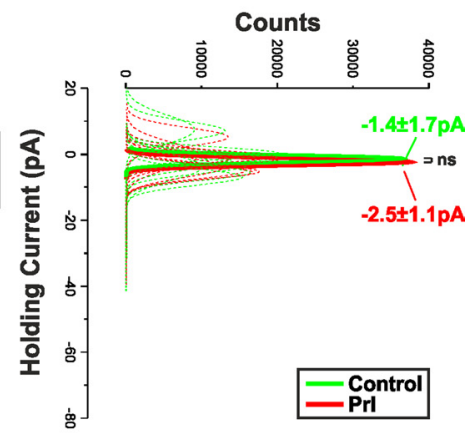

C

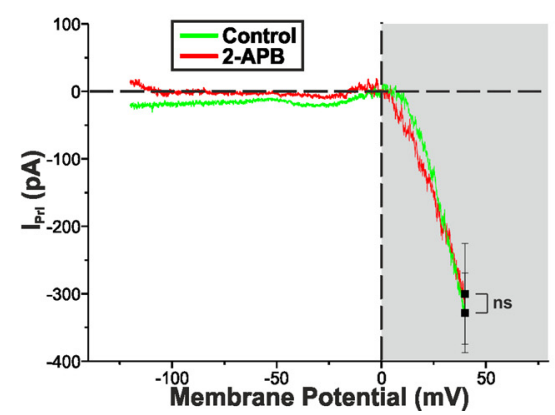

Figure 4. The LV component of $I_{\mathrm{Prl}}$ is abolished by 2-APB. $\boldsymbol{A}$, Voltage-clamp recording of an oscillator neuron in the presence of TTX and 2-APB $(200 \mu \mathrm{m})$. Application of Prl failed to induce an inward current. To the right, sharing its $y$-axis with the raw trace, are Gaussian fits of averaged (solid lines) holding current frequency distributions in control (green) and Prl (red). Raw data used to produce averages shown as dashed lines. $\boldsymbol{B}$, Averaged voltage-clamp ramps recorded in the presence of 2-APB (200 $\mu \mathrm{m} ; n=9)$ acquired in control (green) and at the peak of the Prl response (red). $\boldsymbol{C}$, Prl-induced current obtained by the digital subtraction of the traces displayed in $\boldsymbol{B}$. Note the marked reduction in inward current throughout the LV but not HV range.

and has a negative slope conductance around $-50 \mathrm{mV}$ (Fig. $3 C$, $\mathbf{O}$ ), we suspected the involvement of a mixed cationic current (MCC), possibly mediated by the activation of transient receptor potential (TRP) channels (Strübing et al., 2001).

\section{The LV component of $I_{P r l}$ is} underpinned by the activation of a 2-APB-sensitive MCC

To test this hypothesis, $\operatorname{Prl}(500 \mathrm{~nm})$ was applied to TIDA neurons in the presence of TTX (500 nM) and 2-APB $(200 \mu \mathrm{M})$, a potent blocker of TRPC1, TRPC3, TRPC4, TRPC5, and TRPC6 channels (Clapham et al., 2005); however, it should be noted that 2-APB-dependent inhibitions of $\mathrm{IP}_{3}$ receptor and gap junction signaling have also been reported (Maruyama et al., 1997; Harks et al., 2003). Under these conditions, the Prl-induced inward current was almost completely abolished $\left(V_{\text {Hold }}=-60 \mathrm{mV}\right.$; $-1.1 \pm 1.0 \mathrm{pA} ; n=9 ; p<0.005 \mathrm{vs}$ control), undergoing a $93.6 \pm 2.8 \%$ reduction (Fig. $4 A)$. A blocker of TRPC6 and TRPC7 channels, SKF96365 (50 $\mu \mathrm{M})$ (Merritt et al., 1990; Zhu et al., 1998), was also tested. Pretreatment with this compound failed to induce a statistically significant inhibition $(-25.5 \pm 15.6 \%)$ of $I_{\mathrm{Prl}}\left(V_{\mathrm{Hold}}=-60\right.$ $\mathrm{mV} ;-12.9 \pm 2.7 \mathrm{pA} ; n=5 ; p>0.05$ vs control). Interestingly, additional examination of the resultant $I-V$ relationships demonstrated that 2-APB-induced inhibition of $I_{\mathrm{Prl}}$ was restricted to the LV portion, leaving the HV component untouched (Fig. $4 B, C)$. This fact is illustrated by the failure of 2-APB to induce a significant change in $I_{\mathrm{Prl}}$ at $V_{\text {Hold }}=+40 \mathrm{mV}(-300.2 \pm 74.7 \mathrm{pA}$; $n=9 ; p>0.05$ vs control; Fig. $4 C)$ and underscores the distinct nature of the two components.

The contribution of different cations to the Prl-activated 2-APB-sensitive MCC was examined through ionic substitution experiments. The removal of extracellular $\mathrm{Na}^{+}$, via its equimolar substitution with the impermeant cation Tris, reduced $I_{\mathrm{Prl}}$ $\left(V_{\text {Hold }}=-60 \mathrm{mV} ;-4.7 \pm 0.7 \mathrm{pA} ; n=5\right.$; $p<0.005$ vs control) by $73.2 \pm 3.8 \%$ (Fig. $5 A)$. Conversely, the application of $\mathrm{Prl}$ in the presence of low- $\mathrm{Ca}^{2+} /$ high- $\mathrm{Mg}^{2+}$ extracellular recording solution augmented $I_{\text {Prl }}\left(V_{\text {Hold }}=-60 \mathrm{mV} ;-39.4 \pm 9.4 \mathrm{pA}\right.$; $n=7 ; p<0.05$ vs control) by $126.8 \pm$ $54.1 \%$ (Fig. 5B). Together, these data suggest that, at a holding potential of -60 $\mathrm{mV}, \mathrm{Na}^{+}$is the principal charge carrier for $I_{\mathrm{Prl}}$ and that this current appears similar to previously described MCCs mediated through the activation of TRP channels (Strübing et al., 2001; Tsujino et 
al., 2005; Faber et al., 2006; Ramsey et al., 2006; Meis et al., 2007; Chung and Moore, 2009).

\section{Prl broadens TIDA APs}

It seems, therefore, that at resting membrane potential Prl initiates the switch from phasic to tonic firing through the activation of a 2-APB sensitive, $\mathrm{Na}^{+}$dominated MCC. At membrane potentials positive to $0 \mathrm{mV}$ (HV), however, an additional 2-APB-insensitive component of $I_{\mathrm{Prl}}$ becomes active, producing a comparatively large inward current confounding the reversal of the MCC. Because the $\mathrm{HV}$ component of $I_{\mathrm{Prl}}$ falls within the membrane potential range of AP discharge, we investigated the effects of Prl on AP dynamics.

Because conditions for AP discharge in phasic (oscillation up state) and tonic (Prl effect) firing are different, we first sought to determine appropriate points of comparison. The first APs of the oscillation up state are discharged after a period of pronounced hyperpolarization (Lyons et al., 2010). Accordingly, for these initial APs, sodium channel de-inactivation may be assumed to be greater than for the APs later in the up state and APs discharging tonically at the peak of the Prl response. As a result, spikes at the beginning of the up state have greater amplitude and shorter duration and are therefore unsuitable for comparison with spikes during tonic discharge (Fig. 6A,B). To control for this state-dependent variation, AP am-

plitude and threshold between control and Prl effect was paired. Briefly, up state APs within $\pm 2.5 \mathrm{mV}$ of the mean AP amplitude as observed during peak Prl response were selected, and only groups of 10 with statistically similar $(p>0.05)$ amplitudes and thresholds were used for analysis. Using these criteria, we found that Prl significantly increased AP width (defined as spike width $20 \mathrm{mV}$ above threshold) by $18.6 \pm 2.2 \%(n=5 ; p<$ 0.005 vs control $)$ and area by $16.1 \pm 2.3 \%(n=5 ; p<0.005$ vs control; Fig. 6C, Table 1). The constant threshold and amplitude and typical Prl-induced variation in AP rise and decay are represented in the orbital plots in Figure $6 D$.

\section{The HV component is sensitive to extracellular $\mathrm{Ca}^{+}$}

What ionic mechanisms mediate the HV component of $\mathrm{I}_{\mathrm{Prl}}$ ? After entering $\mathrm{HV}$ range, $I_{\mathrm{Prl}}$ slope undergoes a dramatic change of direction (Fig. 3C), a voltage-dependent effect, suggesting either the augmentation of an inward current or the attenuation of an outward current. As in other systems, it has been shown that AP broadening can be caused by the enhanced activation of voltagedependent calcium channels (VDCCs), the role of $\mathrm{Ca}^{2+}$ influx was investigated. In addition to the enhancement of $I_{\mathrm{Prl}}$ at $V_{\mathrm{Hold}}$ $=-60 \mathrm{mV}$ (Fig. $7 A$ ), additional examination of the $I-V$ relationship of $I_{\mathrm{Prl}}$ in low-Ca ${ }^{2+} /$ high- $\mathrm{Mg}^{2+}$ revealed a reduced $\mathrm{HV}$ component, with $I_{\mathrm{Prl}}$ at $+40 \mathrm{mV}$ being $-50.5 \pm 44.4 \mathrm{pA}(n=7$; Fig. $7 B)$, a value statistically different from control $(p<0.01)$. Because this reduction in $\mathrm{HV}$ component of $I_{\mathrm{Prl}}$ could simply be a
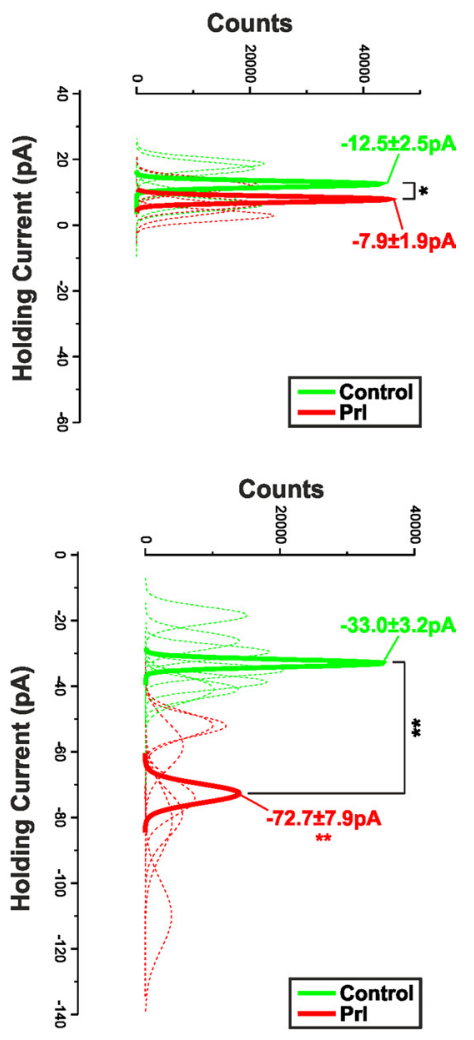

Figure 5. The $\mathrm{LV}$ component of $I_{\mathrm{Prl}}$ is mediated by a $\mathrm{Na}^{+}$-dominated MCC. $\boldsymbol{A}$, Voltage-clamp recording of an oscillating TIDA ( sharing its $y$-axis with the raw trace, are Gaussian fits of averaged (solid lines) holding current frequency distributions in control (green) and $\operatorname{Prl}\left(\right.$ red). Raw data used to produce averages shown as dashed lines $(n=7) .{ }^{*} p<0.05,{ }^{* *} p<0.01$.

consequence of the low- $\mathrm{Ca}^{2+} /$ high- $\mathrm{Mg}^{2+}$ enhanced MCC (Fig. $7 A$ ), we sought to determine the effect of directly blocking VDCCs. Bath application of nimodopine $(10 \mu \mathrm{M})$, a selective blocker of L-type VDCCs, resulted in an even greater diminution of the HV component $(83.6 \pm 67.1 \mathrm{pA} ; n=5 ; p<0.005$ vs control), an effect so large as to enable $I_{\mathrm{Prl}}$ to reverse at $\sim 0 \mathrm{mV}$ (Fig. $7 B$ ). In contrast, nimodopine failed to affect the LV component (Fig. $7 A, B$ ). These results demonstrate a role for $\mathrm{Ca}^{2+}$ entry via L-type VDCCs in the HV component of $I_{\mathrm{Prl}}$.

\section{$\mathrm{BK} \mathrm{Ca}^{+}$-activated $\mathrm{K}^{+}$currents are involved in the generation of $\mathrm{HV} \boldsymbol{I}_{\mathrm{Prl}}$}

We had yet to address the possibility that the HV component of $I_{\mathrm{Prl}}$ could be underpinned by the modulation of a current coupled to the influx of extracellular $\mathrm{Ca}^{2+}$ and active in the $\mathrm{HV}$ range, e.g., $\mathrm{BK} \mathrm{Ca}^{+}$-activated $\mathrm{K}^{+}$currents. To investigate this, $\mathrm{K}^{+}$channels were blocked by the use of $\mathrm{Cs}^{+}$-gluconate-based pipette solution. As expected, blockade of $\mathrm{K}^{+}$channels did not produce a statistically significant effect on $I_{\mathrm{Prl}}$ at $V_{\mathrm{Hold}}=-60 \mathrm{mV}(-27.3 \pm 7.4$ $\mathrm{pA} ; n=6 ; p>0.05$ vs control). It did, however, induce a significant reduction in the $\mathrm{HV}$ component, with $I_{\mathrm{Prl}}$ at $+40 \mathrm{mV}=$ $22.4 \pm 19.7 \mathrm{pA}(n=6$; $p<0.005$ vs control; Fig. $7 C)$. Similarly, bath application of the broad-spectrum $\mathrm{K}^{+}$channel blocker TEA (10 mM) significantly affected the HV component of $I_{\mathrm{Prl}}\left(V_{\mathrm{Hold}}=+40 \mathrm{mV} ; 74.1 \pm 33.5 \mathrm{pA} ; n=7 ; p<0.005 \mathrm{vs}\right.$ control; Fig. 7C) but failed to influence the LV component ( $V_{\mathrm{Hold}}$ $=-60 \mathrm{mV} ;-24.7 \pm 6.4 \mathrm{pA} ; n=7 ; p>0.05$ vs control). Thus, 
A

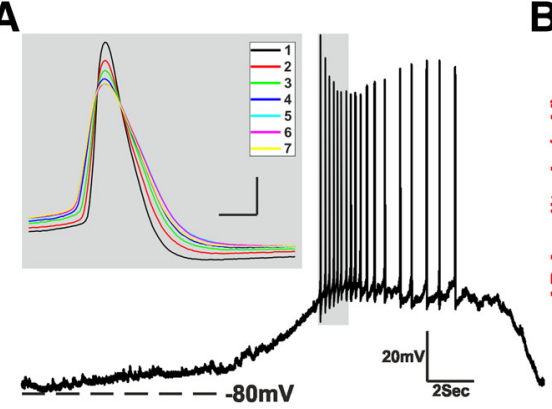

B

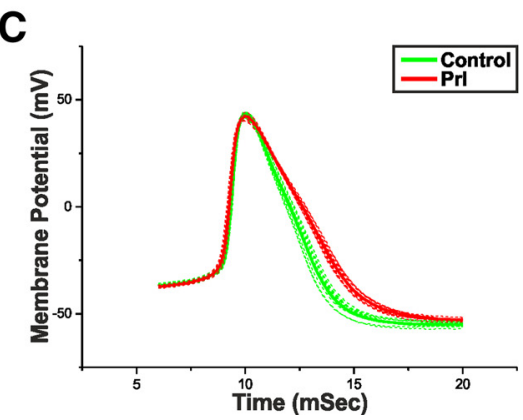

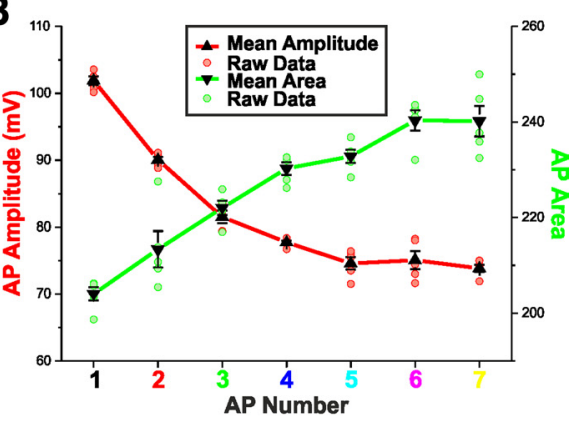

D

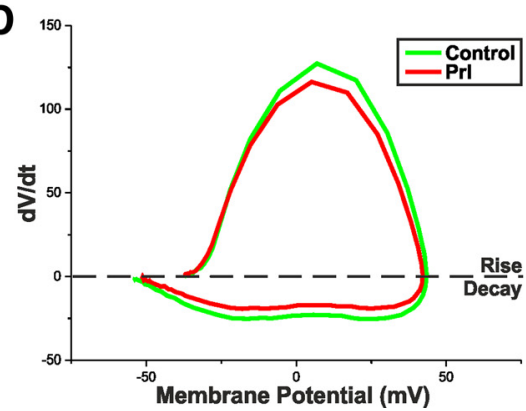

Figure 6. Prl broadens TIDA APs. $\boldsymbol{A}$, Current-clamp recording of a TIDA neuron up state. Gray inset, An expanded superimposition of the first seven peak-aligned APs demonstrating variation in waveform properties. $\boldsymbol{B}$, Mean \pm SEM of the AP amplitude (red) and AP area (green) of the first seven APs of five consecutive up states from five different TIDA neurons. Amplitude and area achieved statistical significance compared with AP1 from AP2 onward. C, Average AP waveforms from a TIDA neuron in control (green) and $\operatorname{Prl}($ red; $500 \mathrm{~nm} ; n=10$ ). Raw data used to produce averages shown as dashed lines. To control for the variation in AP properties, only groups with statistically similar amplitudes and thresholds were used for analysis. Note the Prl-induced broadening of the AP. D, Phase plots of the average AP waveforms depicted in C. Note the Prl-induced changes in rise and decay.

Table 1. AP potential properties

\begin{tabular}{llllll}
\hline$n=5$ & Control & Prl & Difference & \% Change & Significance \\
\hline $\begin{array}{l}\text { Area } \\
\text { Width } \\
\quad \text { (mSec) }\end{array}$ & $3.45 \pm 0.21$ & $4.09 \pm 0.26$ & $0.64 \pm 0.08$ & $18.45 \pm 2.19$ & $p<0.005$ \\
$\begin{array}{c}\text { Half-width } \\
\quad(m S e c)\end{array}$ & $2.88 \pm 0.19$ & $3.40 \pm 0.26$ & $0.52 \pm 0.09$ & $17.86 \pm 2.85$ & $p<0.01$ \\
$\begin{array}{c}\text { Threshold } \\
\text { (mV) }\end{array}$ & $-34.1 \pm 1.8$ & $-34.6 \pm 2.0$ & $-0.6 \pm 0.4$ & $1.5 \pm 1.0$ & NS \\
$\begin{array}{c}\text { Amplitude } \\
(\mathrm{mV})\end{array}$ & $79.8 \pm 2.5$ & $79.1 \pm 2.4$ & $-0.7 \pm 0.3$ & $-0.8 \pm 0.3$ & $\mathrm{NS}$
\end{tabular}

blocking $\mathrm{K}^{+}$currents in both control and test removes the inhibition of $\mathrm{K}^{+}$currents from the Prl effect, allowing $I_{\mathrm{Prl}}$ to reverse (at approximately $-25 \mathrm{mV}$ ) and reveal a greater proportion of the MCC at depolarized potentials.

Having identified a role for both $\mathrm{Ca}^{2+}$ and $\mathrm{K}^{+}$current in the generation of the $\mathrm{HV}$ component of $I_{\mathrm{Prl}}$ and because $\mathrm{Ca}^{2+}$ activated BK-type $\mathrm{K}^{+}$channels are expressed in the rat Arc (Salzmann et al., 2010), we sought to determine a role for BK currents $\left(I_{\mathrm{BK}}\right)$ in the generation of $\mathrm{HV} I_{\mathrm{Prl}}$. The application of the selective BK blocker paxilline $(2 \mu \mathrm{M})$ (Sanchez and McManus, 1996) did not significantly alter the Prl-induced inward current at $V_{\text {Hold }}=$ $-60 \mathrm{mV}(-14.5 \pm 3.2 \mathrm{pA} ; n=8 ; p>0.05$ vs control). It did, however, in a manner similar to $\mathrm{Cs}^{+}$loading and TEA, affect the $\mathrm{HV}$ component, inducing a transient reversal at approximately $-25 \mathrm{mV}$ and reducing $I_{\mathrm{Prl}}$ at $+40 \mathrm{mV}$ to $-27.5 \pm 22.9 \mathrm{pA}(n=8$; $p<0.005$ vs control; Fig. 7D). Blockade of SK channels with the inclusion of the selective SK channel blocker UCL1684 (1 $\mu \mathrm{M})$ (Dunn, 1999) failed to significantly affect $I_{\mathrm{Prl}}$ at either $V_{\mathrm{Hold}}=$ $-60 \mathrm{mV}(-18.7 \pm 3.5 \mathrm{pA} ; n=8 ; p>0.05$ vs control $)$ or $V_{\text {Hold }}=$
$+40 \mathrm{mV}(-181.1 \pm 43.7 \mathrm{pA} ; n=6 ; p>$ 0.05 vs control; Fig. $7 D)$. In light of these results, it appears that Prl mediates a proportion of its effects in the $\mathrm{HV}$ range through the inhibition of $I_{\mathrm{BK}}$, coupled at least in part to $\mathrm{Ca}^{2+}$ influx via L-type VDCCs.

\section{Wortmannin inhibits the $\mathrm{HV}$-activated component of $I_{\mathrm{Prl}}$}

Activation of Prl receptors initiates a complicated second-messenger cascade. As with other members of the class I cytokine receptor superfamily, e.g., Ob-Rb, this involves numerous signal transduction pathways, including Janus kinase (JAK)/ signal transducer and activator of transcription and phosphoinositide 3-kinase (PI3K) (Grattan et al., 2001; Ma et al., 2005a,b). Surprisingly, the JAK inhibitor AG490 $(10 \mu \mathrm{M})$, a compound known to inhibit the rapid TRPC-dependent effects of leptin in Arc pro-opiomelanocortin (POMC) and kisspeptin neurons (Qiu et al., 2010, 2011), failed to block the Prlinduced inward current $\left(V_{\mathrm{Hold}}=-60\right.$ $\mathrm{mV} ;-23.5 \pm 5.1 \mathrm{pA} ; n=4 ; p>0.05$ vs control), nor did it significantly alter the $\mathrm{HV}$ component of $I_{\mathrm{Prl}}\left(V_{\mathrm{Hold}}=+40 \mathrm{mV}\right.$; $-209.8 \pm 108.7 \mathrm{pA} ; n=3 ; p>0.05$ vs control; Fig. 8). The enzyme PI3K is also known to be essential for both the rapid TRPC-dependent effects of leptin in POMC and kisspeptin neurons (Qiu et al., 2010, 2011) and the membrane insertion of TRPC channels (Bezzerides et al., 2004). A 15 min preincubation with the potent and irreversible PI3K inhibitor wortmannin (200 nM), like AG490, failed to inhibit $I_{\mathrm{Prl}}$ at $V_{\mathrm{Hold}}=-60 \mathrm{mV}(-18.9 \pm 3.2 \mathrm{pA} ; n=8 ; p>$ 0.05 vs control), it did however abolish the HV component $\left(V_{\text {Hold }}\right.$ $=+40 \mathrm{mV} ; 220.9 \pm 119.5 \mathrm{pA} ; n=5 ; p>0.005$ vs control; Fig. 8 ), allowing the remaining $I_{\mathrm{Prl}}$ to reverse (approximately $-25 \mathrm{mV}$; Fig. 8). These data imply that the various components of $I_{\mathrm{Prl}}$ are regulated by distinct signal transduction pathways.

Because the LV and HV components of $I_{\mathrm{Prl}}$ appear to be activated by distinct signal transduction mechanisms, we sought to determine whether they also exhibited differential concentration dependence. To this end, we applied Prl at the concentration of $40 \mathrm{~nm}$, a value appreciably below our $\mathrm{EC}_{50}$ value. Interestingly, at this concentration, we observed two distinct responses. In $68 \%$ ( $n=13$ of 19 ) of neurons, both the LV and HV components were present (Fig. $8 \mathrm{~B}$ ). Moreover, the ratio between $I_{\mathrm{Prl}}$ at $V_{\mathrm{Hold}}=$ $+40 \mathrm{mV}$ and $V_{\text {Hold }}=-60 \mathrm{mV}$ was not significantly different from control ( $500 \mathrm{~nm}$ Prl, $25.5 \pm 4.8, n=11 ; 40 \mathrm{~nm}$ Prl, $31.0 \pm$ $7.8, n=13 ; p>0.05)$. The remaining neurons $(32 \% ; n=6$ of 19$)$ displayed the LV component only, reversing at a membrane potential of $-31.2 \pm 5.0 \mathrm{mV}$. These data suggest the possibility that the LV and HV components may have a differential sensitivity to Prl dose.

\section{Discussion}

Prl has well-recognized actions in the CNS on both the physiology and behavior of the postconception phase of reproduction (Grattan, 2002), as well as powerful central feedback actions on its own secretion (Ben-Jonathan and Hnasko, 2001). The cellular 
mechanisms underlying these processes remain enigmatic. Here, we describe for the first time Prl actions on the membrane properties of CNS neurons. We focused on TIDA neurons, because they constitute the central component of short-loop feedback in the lactotrophic axis and express high levels of Prl receptors (Kokay and Grattan, 2005). Recently, TIDA cells were demonstrated to form a network that discharges in synchronized oscillations (Lyons et al., 2010). We now show that, in the presence of Prl, phasic firing is replaced by tonic discharge. The underlying excitation is reversible and dose dependent. The issue of direct or indirect Prl feedback on TIDA neurons has been controversial (Ben-Jonathan and Hnasko, 2001). We find that Prl-induced depolarization involves direct, postsynaptic actions because it persists when AP discharge is blocked by TTX. Thus, the present data establish that Prl can elicit marked and sustained effects on electrophysiological parameters in the CNS. The results presented here suggest a novel form of fast feedback in lactotroph control with the sequential recruitment of conductances responsible for depolarization and AP broadening, respectively.

The existence of two components of Prl action was first suggested by the biphasic shape of $I_{\mathrm{Prl}}$ (Fig. $3 C$ ), in which an LV and a HV component could be identified. The inward current responsible for depolarization - the LV component-exhibits a negative slope conductance (approximately $-50 \mathrm{mV}$ ) and is attenuated in $\mathrm{Na}^{+}$-substituted aCSF and augmented in low- $\mathrm{Ca}^{2+} /$ high- $\mathrm{Mg}^{2+}$ aCSF (Qiu et al., 2010). This suggests a $\mathrm{Na}^{+}$-dominated MCC mediated through TRPC channels. The LV component proved sensitive to 2-APB, a blocker of TRPC1, TRPC3, TRPC4, TRPC5, and TRPC6 channels, yet insensitive to SKF96365, a blocker of TRPC6 and TRPC7 channels (Clapham et al., 2005). This pharmacological profile is similar to that reported for the cholecystokinin-activated MCC in rat amygdala interneurons (Chung and Moore, 2009) but distinct from that reported for leptin responses in Arc POMC neurons, effects mediated via the activation of another member of the class I cytokine receptor family, Ob-Rb (Qiu et al., 2010).

The HV component is substantially larger than the LV component and operates in the (temporally more limited) AP range. Examination of spike dynamics revealed a significant broadening of AP width in the presence of $\operatorname{Prl}$ (in APs matched for amplitude and threshold). Our ramp results suggest that the HV component represents either the closing of an outward current and/or the opening of an inward current. Additional pharmacological and ion substitution experiments suggested the former, because
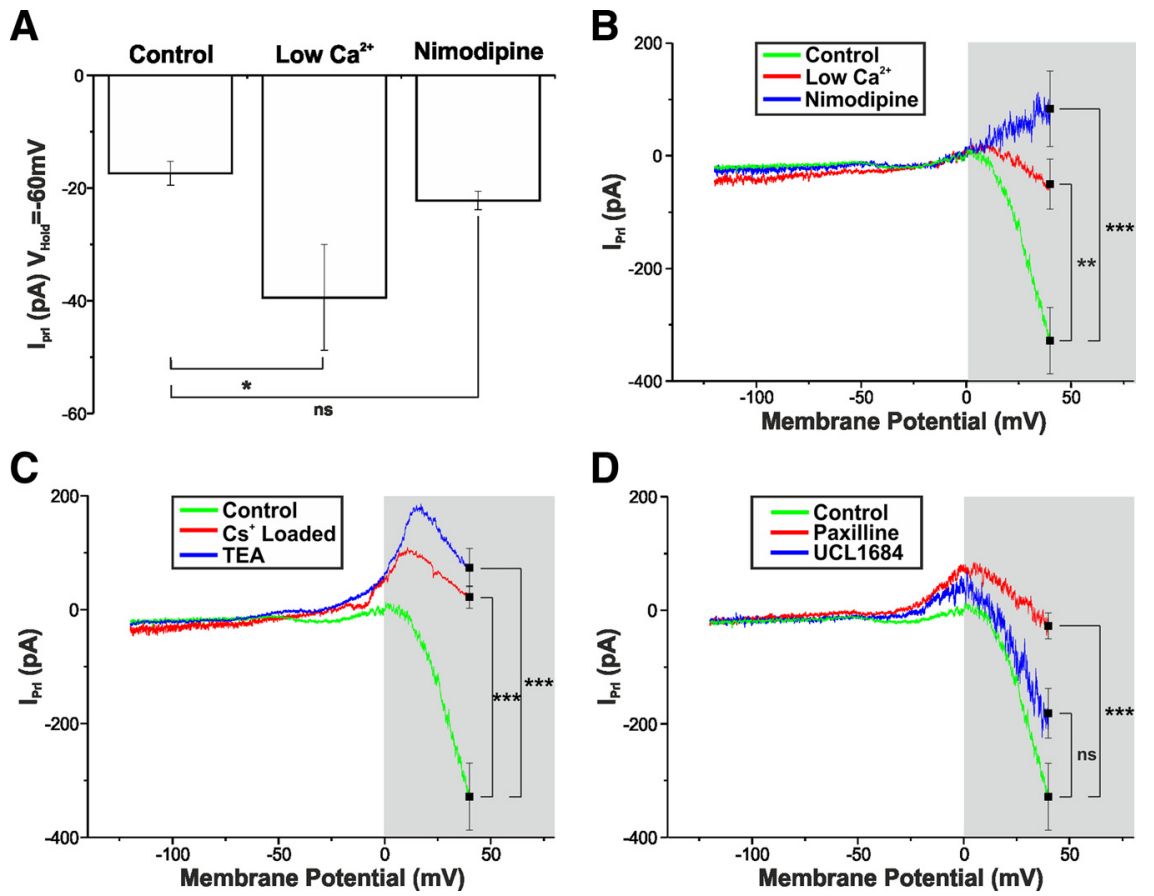

Figure 7. The HV component of $/$ Prl is underpinned by the inhibition of $\mathrm{Ca}^{2+}$-sensitive BK-type $\mathrm{K}^{+}$current. $A$, Summary of the effects of low- $\mathrm{Ca}^{2+} /$ high-Mg ${ }^{2+}$ solution $(n=7)$ and nimodipine $(10 \mu \mathrm{m} ; n=5)$ on $/_{\text {Prl }}$ at $V_{\text {Hold }}=-60 \mathrm{mV}$ to control $(n=11)$. Low- $\mathrm{Ca}^{2+} /$ high-Mg ${ }^{2+}$ solution significantly augments the Prl-induced inward current. Values expressed as mean \pm SEM. ${ }^{*} p<$ 0.05. B, I-V relationship of $I_{\mathrm{Prl}}$ in control (green, $\left.n=14\right)$, low- $\mathrm{Ca}^{2+} / \mathrm{high}^{-\mathrm{Mg}^{2+}}$ solution (red; $\left.n=7\right)$, and nimodipine $(10 \mu \mathrm{M}$; blue; $n=5)$. Both nimodipine and low- $\mathrm{Ca}^{2+} / \mathrm{high}^{-\mathrm{Mg}^{2+}}$ solution significantly modify $\mathrm{I}_{\mathrm{Prl}}$ at $V_{\text {Hold }}=+40 \mathrm{mV}$. Values expressed as mean \pm SEM. ${ }^{* *} p<0.01,{ }^{* * *} p<0.005$. C, I-V relationship of Prl $_{\text {in }}$ control (green; $\left.n=14\right)$, , ${ }^{*}{ }^{+}{ }^{-}$-loaded" solution (red; $n=$ 6), and TEA (10 mm; blue; $n=7)$. Both Cs ${ }^{+}$-loaded solution and TEA significantly modified $I_{\text {Prl }}$ at $V_{\text {Hold }}=+40 \mathrm{mV}$. Values expressed as mean $\pm S E M .{ }^{* * *} p<0.005 . D, I-V$ relationship of $I_{\text {Prl }}$ in control (green; $\left.n=14\right)$, paxilline $(2 \mu \mathrm{m} ;$ red; $n=8)$, and UCL1684 (1 $\mu \mathrm{m}$; blue; $n=6$ ). Paxilline, but not UCL1684, significantly modified $I_{\text {Prl }}$ at $V_{\text {Hold }}=+40 \mathrm{mV}$. Values expressed as mean \pm SEM. ${ }^{* * *} p<0.005$.
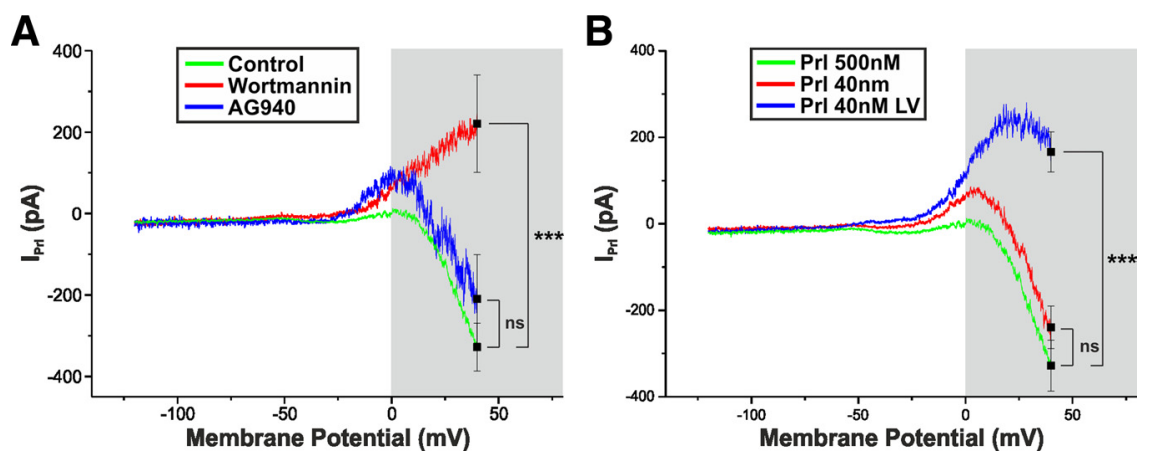

Figure 8. The $L V$ and $H V$ components of $/_{\mathrm{Prl}}$ are activated by distinct signal transduction pathways. $A, I-V$ relationship of $I_{\mathrm{Prl}}$ in control (green; $n=14)$, wortmannin (200 nм; red; $n=8)$, and AG490 (10 $\mu \mathrm{m} ;$ blue; $n=3)$. Wortmannin, but not AG490, significantly modifies $I_{\mathrm{Prl}}$ at $V_{\text {Hold }}=+40 \mathrm{mV}$. Values expressed as mean $\pm \mathrm{SEM}$. ${ }^{* * *} p<0.005$. B, I-V relationship of $I_{\mathrm{Prl}}$ at a concentration of $500 \mathrm{~nm} \operatorname{Prl}$ (green; $n=14), 40 \mathrm{~nm}$ Prl in which both the LV and HV components were present (red; $n=13$ of 19), and $40 \mathrm{~nm}$ Prl in which only the LV component was present (blue; $n=6$ of 19). Values expressed as mean \pm SEM. ${ }^{* * *} p<0.005$.

blockade of $\mathrm{K}^{+}$channels by TEA or $\mathrm{Cs}^{2+}$ attenuated the HV component (present results). One powerful means of delaying AP repolarization is by inhibition of BK-type $\mathrm{K}^{+}$channels (Storm, 1987; Golding et al., 1999). Furthermore, BK channel opening probability is highest in the HV range $(+20-40 \mathrm{mV})$ (Latorre et al., 1989). Indeed, incubation with the BK-specific antagonist paxilline (Knaus et al., 1994) blocked the HV component to a similar extent as TEA/Cs ${ }^{2+}$ blockade [whereas inhibition of SK-type $\mathrm{K}^{+}$channels by the specific antagonist UCL1684 (Campos Rosa et al., 2000) had no significant effect]. These find- 
ings indicate that Prl-induced broadening of APs may be mediated by closure of BK channels.

In our experiments, the HV component was significantly diminished in low-Ca ${ }^{2+} /$ high- $\mathrm{Mg}^{2+}$ aCSF or in the presence of the L-type blocker nimodipine. These data suggest that $\mathrm{Ca}^{2+}$ influx via L-type VDCCs is a requirement for the potassium current inhibited by Prl in the HV range. In neurons, BK channels often colocalize to microdomains with L-type $\mathrm{Ca}^{2+}$ channels (Grunnet and Kaufmann, 2004; Berkefeld et al., 2006; Fakler and Adelman, 2008), and $\mathrm{Ca}^{2+}$ influx through the latter is believed to shift $\mathrm{BK}$ voltage dependence to more hyperpolarized potentials. The tight coupling of L-type VDCCs to BK channels has been implicated in other endocrine and neuroendocrine cells with sustained secretion in response to steady depolarization (Prakriya and Lingle, 1999; Marcantoni et al., 2007, 2010) and, in adrenomedullary cells, can be recruited as demands on hormone release increase (Polo-Parada et al., 2006).

With the identification of two Prl-activated conductances operating in distinct parts of the membrane potential spectrum, we propose a novel mechanism for fast short-loop feedback in the lactotrophic axis. First, the opening of a slow inward conductance pushes the TIDA neuron to tonic firing. At this depolarized state, inhibition of BK K ${ }^{+}$conductance(s) lead to a broadening of APs. Broadened APs are well established to increase terminal $\mathrm{Ca}^{2+}$ influx, leading to increased transmitter release (Klein and Kandel, 1980; Llinás et al., 1981; Augustine, 1990; Wheeler et al., 1996; Sabatini and Regehr, 1997). Indeed, previous studies in the cerebellum have shown that seemingly modest changes in AP halfwidth (notably an increase by $19 \%$ as we also observed with $\operatorname{Prl}$ in TIDA cells) results in several-fold augmentation of synaptic transmitter release (Sabatini and Regehr, 1997). In the TIDA system, the effect would be an increased vesicular dopamine release at the terminals in the median eminence. This boosting of dopamine tone in turn leads to enhanced dopamine receptor $\mathrm{D}_{2} \mathrm{R}$ mediated inhibition of the lactotroph, halting Prl release from the pituitary. It has been shown previously that Prl stimulates activity (Arbogast and Voogt, 1995) and transcription (Arbogast and Voogt, 1991; Selmanoff et al., 1991) of TH, which would increase the stores of dopamine available for release. Combined, these effects provide powerful mechanisms for Prl autoinhibition. Notably, whereas AP broadening accomplished by manipulations of ion channels has often been evoked as a means of increasing release (e.g., by TEA) (Sabatini and Regehr, 1997), the Prl-TIDA mechanism proposed here would constitute a rare example of increased spike duration resulting from stimulation by a physiological signal molecule (but not without precedent: Klein and Kandel, 1978; Spanswick and Renaud, 2005). Thus, in situations with inappropriately high serum Prl levels, TIDA cells may fire not only more but also more powerful (in terms of dopamine release) APs, tightening the brake on pituitary Prl release. Additional investigation, e.g., using fast-scan cyclic voltammetry (Robinson et al., 2003), will be necessary to determine the relationship between TIDA neuron discharge pattern and dopamine release into the portal circulation.

In what situations might the mechanisms described here operate? The effective concentrations suggested by our dose-response results (Fig. 2E) are more typical of those observed during pathological hyperprolactinaemia resulting from pituitary adenomas (Eljarmak et al., 1985; Oh and Aghi, 2011) than during circadian variations in the male (Hernandez et al., 2006), fluctuations across the estrus cycle, or during pregnancy, which are substantially lower (Amenomori et al., 1970). Thus, it could be speculated that these electrophysiological actions may primarily play a role in counteracting pathophysiological elevations of $\operatorname{Prl}$ rather than in the physiological variations that are required for normal reproduction. In addition, the feedback response to $\mathrm{Prl}$ in TIDA dopamine output is disrupted during pregnancy to allow for lactation-inducing Prl surges (Grattan and Averill, 1995; Andrews et al., 2001). (An important caveat needs to be emphasized in this context, however: exogenous bath application is likely to be far less efficient than the endogenous vascular route in delivering the hormone to the site of the receptors. It is therefore difficult to estimate the correlation between the doses used in the current study and serum concentrations in the living rat.) It will be of interest to address in future studies to what extent similar actions to those of Prl on membrane properties of TIDA cells can be seen in the feedback from other pituitary hormones on their respective neuroendocrine master neurons. Are these general mechanisms or specific to a system that operates via inhibition, unlike the other hypothalamo-pituitary axes that are regulated by stimulation?

Our data also offer new insight into the signal pathways whereby Prl exerts central actions. Prl receptor signaling is most commonly associated with activation of the JAK2 pathway (Rui et al., 1994; Bole-Feysot et al., 1998) and downstream transcriptional regulation. Although most of what is known about Prl signaling derives from studies of mammary gland and other peripheral organs, there is also evidence of Prl-induced JAK activity in TIDA cells (Ma et al., 2005b). Intriguingly, however, we were unable to modulate the $I_{\mathrm{Prl}}$ using the JAK inhibitor AG490 (Meydan et al., 1996). Thus, the electrophysiological actions of Prl may depend on signaling systems distinct from those mediating the transcriptional and phosphorylatory effects of this hormone. There is, however, also evidence for Prl activating PI3K (al-Sakkaf et al., 1996), a faster signaling pathway potentially more compatible with the relatively short-latency actions observed in TIDA cells (present findings). Intriguingly, the HV component was abolished in the presence of the PI3K inhibitor wortmannin, whereas the LV component remained intact. It may be noted that, in other Arc neurons neighboring the TIDA population, leptin and insulin modulation of BK channels (which may underlie the HV component in the present study; see above) appears to be mediated through PI3K (Yang et al., 2010). Although more studies will be necessary to elucidate the full signal transduction cascade underlying electrophysiological Prl actions on TIDA cells, this observation suggests that the two components of Prl-induced excitation can be modulated separately.

In conclusion, the data presented here provide the first evidence of electrophysiological Prl actions, constituting a compound effect promoting dopamine secretion from TIDA neurons. These results suggest a novel mechanism for feedback in the lactotrophic axis that may help protect against infertility, loss of libido, obesity, and other effects of hyperprolactinaemia.

\section{References}

al-Sakkaf KA, Dobson PR, Brown BL (1996) Activation of phosphatidylinositol 3-kinase by prolactin in Nb2 cells. Biochem Biophys Res Commun 221:779-784.

Amenomori Y, Chen CL, Meites J (1970) Serum prolactin levels in rats during different reproductive states. Endocrinology 86:506-510.

Andrews ZB, Kokay IC, Grattan DR (2001) Dissociation of prolactin secretion from tuberoinfundibular dopamine activity in late pregnant rats. Endocrinology 142:2719-2724.

Arbogast LA, Voogt JL (1991) Hyperprolactinemia increases and hypoprolactinemia decreases tyrosine hydroxylase messenger ribonucleic acid levels in the arcuate nuclei, but not the substantia nigra or zona incerta. Endocrinology 128:997-1005.

Arbogast LA, Voogt JL (1995) Hypoprolactinemia decreases tyrosine hy- 
droxylase activity in the tuberoinfundibular dopaminergic neurons acutely by protein dephosphorylation and chronically by changes in gene expression. Endocrine 3:801-806.

Augustine GJ (1990) Regulation of transmitter release at the squid giant synapse by presynaptic delayed rectifier potassium current. J Physiol 431:343-364.

Ben-Jonathan N, Hnasko R (2001) Dopamine as a prolactin (PRL) inhibitor. Endocr Rev 22:724-763.

Berkefeld H, Sailer CA, Bildl W, Rohde V, Thumfart JO, Eble S, Klugbauer N, Reisinger E, Bischofberger J, Oliver D, Knaus HG, Schulte U, Fakler B (2006) BKCa-Cav channel complexes mediate rapid and localized $\mathrm{Ca}^{2+}$ activated $\mathrm{K}^{+}$signaling. Science 314:615-620.

Bezzerides VJ, Ramsey IS, Kotecha S, Greka A, Clapham DE (2004) Rapid vesicular translocation and insertion of TRP channels. Nat Cell Biol 6:709-720.

Bole-Feysot C, Goffin V, Edery M, Binart N, Kelly PA (1998) Prolactin (PRL) and its receptor: actions, signal transduction pathways and phenotypes observed in PRL receptor knockout mice. Endocr Rev 19:225-268.

Campos Rosa J, Galanakis D, Piergentili A, Bhandari K, Ganellin CR, Dunn PM, Jenkinson DH (2000) Synthesis, molecular modeling, and pharmacological testing of bis-quinolinium cyclophanes: potent, non-peptidic blockers of the apamin-sensitive $\mathrm{Ca}^{2+}$-activated $\mathrm{K}^{+}$channel. J Med Chem 43:420-431.

Chiu S, Wise PM (1994) Prolactin receptor mRNA localization in the hypothalamus by in situ hybridization. J Neuroendocrinol 6:191-199.

Chung L, Moore SD (2009) Cholecystokinin excites interneurons in rat basolateral amygdala. J Neurophysiol 102:272-284.

Clapham DE, Julius D, Montell C, Schultz G (2005) International Union of Pharmacology. XLIX. Nomenclature and structure-function relationships of transient receptor potential channels. Pharmacol Rev 57:427-450.

Dunn PM (1999) UCL 1684: a potent blocker of $\mathrm{Ca}^{2+}$-activated $\mathrm{K}^{+}$channels in rat adrenal chromaffin cells in culture. Eur J Pharmacol 368:119-123.

Eljarmak D, Lis M, Cantin M, Carrière PD, Collu R (1985) Effects of chronic bromocriptine treatment of an estrone-induced, prolactin-secreting rat pituitary adenoma. Horm Res 21:160-167.

Faber ES, Sedlak P, Vidovic M, Sah P (2006) Synaptic activation of transient receptor potential channels by metabotropic glutamate receptors in the lateral amygdala. Neuroscience 137:781-794.

Fakler B, Adelman JP (2008) Control of $\mathrm{K}(\mathrm{Ca})$ channels by calcium nano/ microdomains. Neuron 59:873-881.

Freeman ME, Kanyicska B, Lerant A, Nagy G (2000) Prolactin: structure, function, and regulation of secretion. Physiol Rev 80:1523-1631.

Fuxe K (1964) Cellular localization of monoamines in the median eminence and the infundibular stem of some mammals. Z Zellforsch Mikrosk Anat 61:710-724.

Golding NL, Jung HY, Mickus T, Spruston N (1999) Dendritic calcium spike initiation and repolarization are controlled by distinct potassium channel subtypes in CA1 pyramidal neurons. J Neurosci 19:8789-8798.

Gonzalez HA, Porter JC (1988) Mass and in situ activity of tyrosine hydroxylase in the median eminence: effect of hyperprolactinemia. Endocrinology 122:2272-2277.

Grattan DR (2002) Behavioural significance of prolactin signalling in the central nervous system during pregnancy and lactation. Reproduction 123:497-506.

Grattan DR, Averill RL (1995) Absence of short-loop autoregulation of prolactin during late pregnancy in the rat. Brain Res Bull 36:413-416.

Grattan DR, Xu J, McLachlan MJ, Kokay IC, Bunn SJ, Hovey RC, Davey HW (2001) Feedback regulation of PRL secretion is mediated by the transcription factor, signal transducer, and activator of transcription $5 \mathrm{~b}$. Endocrinology 142:3935-3940.

Grunnet M, Kaufmann WA (2004) Coassembly of big conductance $\mathrm{Ca}^{2+}$ activated $\mathrm{K}^{+}$channels and L-type voltage-gated $\mathrm{Ca}^{2+}$ channels in rat brain. J Biol Chem 279:36445-36453.

Harks EG, Camiña JP, Peters PH, Ypey DL, Scheenen WJ, van Zoelen EJ, Theuvenet AP (2003) Besides affecting intracellular calcium signaling, 2-APB reversibly blocks gap junctional coupling in confluent monolayers, thereby allowing measurement of single-cell membrane currents in undissociated cells. FASEB J 17:941-943.

Hernandez ME, Soto-Cid A, Rojas F, Pascual LI, Aranda-Abreu GE, Toledo R,
Garcia LI, Quintanar-Stephano A, Manzo J (2006) Prostate response to prolactin in sexually active male rats. Reprod Biol Endocrinol 4:28.

Howes OD, Wheeler MJ, Pilowsky LS, Landau S, Murray RM, Smith S (2007) Sexual function and gonadal hormones in patients taking antipsychotic treatment for schizophrenia or schizoaffective disorder. J Clin Psychiatry 68:361-367.

Klein M, Kandel ER (1978) Presynaptic modulation of voltage-dependent $\mathrm{Ca}^{2+}$ current: mechanism for behavioral sensitization in Aplysia californica. Proc Natl Acad Sci U S A 75:3512-3516.

Klein M, Kandel ER (1980) Mechanism of calcium current modulation underlying presynaptic facilitation and behavioral sensitization in Aplysia. Proc Natl Acad Sci U S A 77:6912-6916.

Knaus HG, McManus OB, Lee SH, Schmalhofer WA, Garcia-Calvo M, Helms LM, Sanchez M, Giangiacomo K, Reuben JP, Smith AB 3rd, Kaczorowski GJ, Garcia ML (1994) Tremorgenic indole alkaloids potently inhibit smooth muscle high-conductance calcium-activated potassium channels. Biochemistry 33:5819-5828.

Knegtering H, Boks M, Blijd C, Castelein S, van den Bosch RJ, Wiersma D (2006) A randomized open-label comparison of the impact of olanzapine versus risperidone on sexual functioning. J Sex Marital Ther 32:315-326.

Kokay IC, Grattan DR (2005) Expression of mRNA for prolactin receptor (long form) in dopamine and pro-opiomelanocortin neurones in the arcuate nucleus of non-pregnant and lactating rats. J Neuroendocrinol 17:827-835.

Kokay IC, Bull PM, Davis RL, Ludwig M, Grattan DR (2006) Expression of the long form of the prolactin receptor in magnocellular oxytocin neurons is associated with specific prolactin regulation of oxytocin neurons. Am J Physiol Regul Integr Comp Physiol 290:R1216-R1225.

Latorre R, Oberhauser A, Labarca P, Alvarez O (1989) Varieties of calciumactivated potassium channels. Annu Rev Physiol 51:385-399.

Llinás R, Steinberg IZ, Walton K (1981) Relationship between presynaptic calcium current and postsynaptic potential in squid giant synapse. Biophys J 33:323-351.

Lyons DJ, Horjales-Araujo E, Broberger C (2010) Synchronized network oscillations in rat tuberoinfundibular dopamine neurons: switch to tonic discharge by thyrotropin-releasing hormone. Neuron 65:217-229.

Ma FY, Grattan DR, Goffin V, Bunn SJ (2005a) Prolactin-regulated tyrosine hydroxylase activity and messenger ribonucleic acid expression in mediobasal hypothalamic cultures: the differential role of specific protein kinases. Endocrinology 146:93-102.

Ma FY, Anderson GM, Gunn TD, Goffin V, Grattan DR, Bunn SJ (2005b) Prolactin specifically activates signal transducer and activator of transcription $5 \mathrm{~b}$ in neuroendocrine dopaminergic neurons. Endocrinology 146:5112-5119.

Marcantoni A, Baldelli P, Hernandez-Guijo JM, Comunanza V, Carabelli V, Carbone E (2007) L-type calcium channels in adrenal chromaffin cells: role in pace-making and secretion. Cell Calcium 42:397-408.

Marcantoni A, Vandael DH, Mahapatra S, Carabelli V, Sinnegger-Brauns MJ, Striessnig J, Carbone E (2010) Loss of Cav1.3 channels reveals the critical role of L-type and BK channel coupling in pacemaking mouse adrenal chromaffin cells. J Neurosci 30:491-504.

Maruyama T, Kanaji T, Nakade S, Kanno T, Mikoshiba K (1997) 2APB, 2 -aminoethoxydiphenyl borate, a membrane-penetrable modulator of Ins $(1,4,5) \mathrm{P} 3$-induced $\mathrm{Ca}^{2+}$ release. J Biochem 122:498-505.

Meis S, Munsch T, Sosulina L, Pape HC (2007) Postsynaptic mechanisms underlying responsiveness of amygdaloid neurons to cholecystokinin are mediated by a transient receptor potential-like current. Mol Cell Neurosci 35:356-367.

Meltzer HY, Sachar EJ, Frantz AG (1974) Serum prolactin levels in unmedicated schizophrenic patients. Arch Gen Psychiatry 31:564-569.

Merritt JE, Armstrong WP, Benham CD, Hallam TJ, Jacob R, Jaxa-Chamiec A, Leigh BK, McCarthy SA, Moores KE, Rink TJ (1990) SK\&F 96365, a novel inhibitor of receptor-mediated calcium entry. Biochem J 271:515-522.

Meydan N, Grunberger T, Dadi H, Shahar M, Arpaia E, Lapidot Z, Leeder JS, Freedman M, Cohen A, Gazit A, Levitzki A, Roifman CM (1996) Inhibition of acute lymphoblastic leukaemia by a Jak-2 inhibitor. Nature 379:645-648.

Oh MC, Aghi MK (2011) Dopamine agonist-resistant prolactinomas. J Neurosurg 114:1369-1379.

Pasqualini C, Bojda F, Gaudoux F, Guibert B, Leviel V, Teissier E, Rips R, 
Kerdelhue B (1988) Changes in tuberoinfundibular dopaminergic neuron activity during the rat estrous cycle in relation to the prolactin surge: alteration by a mammary carcinogen. Neuroendocrinology 48:320-327.

Pi XJ, Grattan DR (1998) Distribution of prolactin receptor immunoreactivity in the brain of estrogen-treated, ovariectomized rats. J Comp Neurol 394:462-474.

Polishuk WZ, Kulcsar S (1956) Effects of chlorpromazine on pituitary function. J Clin Endocrinol Metab 16:292-293.

Polo-Parada L, Chan SA, Smith C (2006) An activity-dependent increased role for L-type calcium channels in exocytosis is regulated by adrenergic signaling in chromaffin cells. Neuroscience 143:445-459.

Prakriya M, Lingle CJ (1999) BK channel activation by brief depolarizations requires $\mathrm{Ca}^{2+}$ influx through $\mathrm{L}$ - and Q-type $\mathrm{Ca}^{2+}$ channels in rat chromaffin cells. J Neurophysiol 81:2267-2278.

Qiu J, Fang Y, Rønnekleiv OK, Kelly MJ (2010) Leptin excites proopiomelanocortin neurons via activation of TRPC channels. J Neurosci 30:1560-1565.

Qiu J, Fang Y, Bosch MA, Rønnekleiv OK, Kelly MJ (2011) Guinea pig kisspeptin neurons are depolarized by leptin via activation of TRPC channels. Endocrinology 152:1503-1514.

Ramsey IS, Delling M, Clapham DE (2006) An introduction to TRP channels. Annu Rev Physiol 68:619-647.

Riddle O, Bates RW, Dykshorn SW (1933) The preparation, identification and assay of prolactin—a hormone of the anterior pituitary. Am J Physiol 105:191-216.

Robinson DL, Venton BJ, Heien ML, Wightman RM (2003) Detecting subsecond dopamine release with fast-scan cyclic voltammetry in vivo. Clin Chem 49:1763-1773.

Rui H, Kirken RA, Farrar WL (1994) Activation of receptor-associated tyrosine kinase JAK2 by prolactin. J Biol Chem 269:5364-5368.

Sabatini BL, Regehr WG (1997) Control of neurotransmitter release by presynaptic waveform at the granule cell to Purkinje cell synapse. J Neurosci 17:3425-3435.

Salzmann M, Seidel KN, Bernard R, Prüss H, Veh RW, Derst C (2010) BKbetal subunits contribute to BK channel diversity in rat hypothalamic neurons. Cell Mol Neurobiol 30:967-976.

Sanchez M, McManus OB (1996) Paxilline inhibition of the alpha-subunit of the high-conductance calcium-activated potassium channel. Neuropharmacology 35:963-968.
Selmanoff M, Shu C, Hartman RD, Barraclough CA, Petersen SL (1991) Tyrosine hydroxylase and POMC mRNA in the arcuate region are increased by castration and hyperprolactinemia. Brain Res Mol Brain Res 10:277-281.

Spanswick D, Renaud LP (2005) Angiotensin II induces calcium-dependent rhythmic activity in a subpopulation of rat hypothalamic median preoptic nucleus neurons. J Neurophysiol 93:1970-1976.

Storm JF (1987) Action potential repolarization and a fast afterhyperpolarization in rat hippocampal pyramidal cells. J Physiol 385:733-759.

Strübing C, Krapivinsky G, Krapivinsky L, Clapham DE (2001) TRPC1 and TRPC5 form a novel cation channel in mammalian brain. Neuron 29:645-655.

Townsend J, Cave BJ, Norman MR, Flynn A, Uney JB, Tortonese DJ, Wakerley JB (2005) Effects of prolactin on hypothalamic supraoptic neurones: evidence for modulation of STAT5 expression and electrical activity. Neuro Endocrinol Lett 26:125-130.

Tsujino N, Yamanaka A, Ichiki K, Muraki Y, Kilduff TS, Yagami K, Takahashi S, Goto K, Sakurai T (2005) Cholecystokinin activates orexin/hypocretin neurons through the cholecystokinin A receptor. J Neurosci 25:7459-7469.

Van Goor F, Zivadinovic D, Martinez-Fuentes AJ, Stojilkovic SS (2001) Dependence of pituitary hormone secretion on the pattern of spontaneous voltage-gated calcium influx. Cell type-specific action potential secretion coupling. J Biol Chem 276:33840-33846.

Wheeler DB, Randall A, Tsien RW (1996) Changes in action potential duration alter reliance of excitatory synaptic transmission on multiple types of $\mathrm{Ca}^{2+}$ channels in rat hippocampus. J Neurosci 16:2226-2237.

Yang MJ, Wang F, Wang JH, Wu WN, Hu ZL, Cheng J, Yu DF, Long LH, Fu $\mathrm{H}$, Xie N, Chen JG (2010) PI $3 \mathrm{~K}$ integrates the effects of insulin and leptin on large-conductance $\mathrm{Ca}^{2+}$-activated $\mathrm{K}^{+}$channels in neuropeptide $\mathrm{Y}$ neurons of the hypothalamic arcuate nucleus. Am J Physiol Endocrinol Metab 298:E193-E201.

Zhu X, Jiang M, Birnbaumer L (1998) Receptor-activated $\mathrm{Ca}^{2+}$ influx via human Trp3 stably expressed in human embryonic kidney (HEK)293 cells. Evidence for a non-capacitative $\mathrm{Ca}^{2+}$ entry. J Biol Chem 273:133142. 